\title{
OS NOVOS ESPAÇOS DE ACUMULÇÃO DO GRUPO VOTORANTIM
}

\section{The new spaces of accumulation of the Votorantim Group}

\author{
Leandro Bruno SANTOS 1
}

\section{RESUMO}

Este artigo está voltado à compreensão das recentes mudanças no capitalismo industrial brasileiro, particularmente a expansão de empresas e grupos no exterior. $O$ recorte de análise deste texto é o Grupo Votorantim, um dos mais importantes conglomerados do país e da América Latina. O grupo atua em diversos ramos da economia e, recentemente, tem investido na aquisição de empresas estrangeiras em diferentes negócios e em diferentes países. Neste artigo, serão apontadas as teorias da internacionalização de empresas e grupos e a trajetória histórica do Grupo Votorantim desde sua origem até a internacionalização de sua produção. Os dados secundários foram obtidos a partir de relatórios anuais do grupo, de revistas especializadas e de jornais.

Palavras-chave: Produção do espaço; Dinâmicas territoriais; Globalização; Grupo Votorantim; Brasil.

\section{ABSTRACT}

This article aims to getting at the recent changes in Brazilian industrial capitalism, especially the expansion of companies and business groups abroad. The analyzed theme is the Votorantim Group, one of the most important groups in the country and Latin America. The Group acts in several branches of the economy and it has recently invested in the acquisition of foreign companies in different business and countries. In this article, the theories of internationalization of companies and business groups and the path of the Votorantim Group are focused - from its origin to productive internationalization. The secondary data were compiled from annual reports of the group, specialized magazines and newspapers.

Keywords: Production of space; Territorial dynamics; Globalization; Votorantim Group; Brazil. 


\section{INTRODUÇÃO}

O objetivo subjacente ao artigo é compreender as recentes transformações por que o capitalismo industrial brasileiro tem passado, sobretudo em função da abertura econômica desenfreada e da consequente reestruturação industrial com o avanço de empresas e grupos brasileiros no exterior. O recorte empírico compreende as estratégias econômicas e espaciais realizadas pelo Grupo Votorantim, um dos mais importantes conglomerados do Brasil e da América Latina.

A crise da dívida externa e do desenvolvimento estatal encerrou os mais de 50 anos de apoio do Estado brasileiro à industrialização e à consolidação de importantes grupos nacionais. Nos anos 1980, a palavra de ordem passou a ser, então, um Estado mínimo, a privatização e concessão de empresas à iniciativa privada, a abertura econômica desenfreada sem um time para cada setor, a desregulamentação econômica e financeira etc. Essas mudanças políticas e econômicas ocasionaram uma reestruturação econômica e patrimonial profunda no setor industrial brasileiro. Inicialmente, houve o avanço de empresas multinacionais no país e a focalização das ações das empresas nacionais ou falência e venda dos ativos e, posteriormente, as empresas brasileiras promoveram um rápido movimento de internacionalização produtiva.

É importante salientar que o avanço de empresas e grupos tupiniquins não é um fenômeno novo, tampouco restrito apenas ao Brasil. Em primeiro lugar, houve em torno de três ondas de investimentos externos de empresas situadas na periferia do sistema capitalista (CHUDNOVSKY; LÓPEZ, 2000), desde meados dos anos 1960. Em segundo lugar, apesar da importância que o Brasil assumiu na América Latina quanto aos investimentos externos, muitas empresas na Ásia têm tido um respeitável destaque no cenário internacional.

Nos últimos anos, aumentou o número de empresas multinacionais sediadas em países periféricos. Os dados disponibilizados pela UNCTAD (Conferência das Nações Unidas para o Comércio e o Desenvolvimento) demonstram que o número de multinacionais dos países periféricos mais que triplicou, saltando de $8,47 \%$ em 1992 para $28,10 \%$ em 2005. Os fluxos de IDE (Investimentos Diretos Estrangeiros) cresceram mais de dez vezes, alcançando mais de US\$130 bilhões anuais, ao passo que os estoques de IDE saltaram de $8,2 \%$ do total mundial para algo em torno de 16\% (UNCTAD, 2008).

Portanto, na batalha capitalista pela concentração da oferta, sobretudo com o acirramento da concorrência oligopólica, empresas situadas na periferia do sistema capitalista têm desempenhado um papel importante. Em termos setoriais, na América Latina o avanço tem sido em setores com tecnologias maduras e naqueles ligados aos recursos naturais, enquanto na Ásia, onde o Estado disciplinou o capital e o trabalho no processo de catching up, conduzindo a um upgrade tecnológico, as empresas estão avançando internacionalmente em setores mais avançados tecnologicamente (KIM, 1997; SANTOS, 2008).

\section{TEORIAS DA INTERNACIONALIZAÇÃO DE EMPRESAS}

Atualmente, os estudos voltados à análise do avanço de empresas e grupos no cenário internacional estão polarizados em três abordagens teóricas elaboradas para explicar a realidade de países desenvolvidos. $\mathrm{Na}$ Inglaterra, a partir da University of Reading, são produzidos trabalhos cujo enfoque é econômico e baseado nas vantagens das empresas. Na Suécia, no âmbito da University of Uppsala, os trabalhos estão assentados no comportamento das empresas, no papel dos empresários e nas diferenças culturais e socioeconômicas. Finalmente, nos Estados Unidos, em particular na Univerisity of Harvard, o enfoque recai sobre a globalização dos mercados e das estratégias das empresas.

Johanson e Vahlme (1977), ao analisarem o avanço de empresas suecas, propõem uma interpretação teórica que leva em conta a dimensão comportamental dos empresários. Com isso, defendem que as empresas se internacionalizam de maneira gradual e incremental. É gradual porque os investimentos externos ocorrem em várias etapas até atingir a instalação de uma unidade produtiva. É incremental porque, à medida que a empresa se expande gradualmente, ela adquire conhecimentos e habilidades que permitem a entrada em outros mercados.

Dunning (1973) defende uma proposição inversa à abordagem comportamental ao privilegiar a dimensão econômica. Para ele, os investimentos produtivos no exterior podem ser explicados a partir de três vantagens controladas pelas empresas. As vantagens são de propriedade dos ativos, de internalização das atividades econômicas e de localização das subsidiárias. Esses três elementos seriam, na opinião do autor, fundamentais nas decisões das empresas para o investimento produtivo no exterior.

A primeira reúne as vantagens de propriedade, envolvendo aspectos estruturais da propriedade dos 
ativos (patentes, inovações e competências) e aspectos transnacionais (vantagens na administração de ativos dispersos). A segunda vantagem, de internalização, é decorrente da integração das sucursais dentro da própria hierarquia da empresa. A última vantagem, de localização, envolve a importância das matérias-primas, da mão de obra barata e qualificada, do tamanho do mercado, dos custos de infraestrutura etc.

Mais recentemente, houve o delineamento de uma terceira vertente teórica cujas atenções estão voltadas à estratégia e à estrutura e/ou arquitetura organizacional das empresas, tendo como fulcro a defesa de que, com o mundo globalizado e a competição global, os executivos à frente das empresas e grupos precisam, não só em seus modos de pensar, mas também nas formas de agir, ser globais (OHMAE, 1985; BARTLETT; GHOSHAL, 1989; PORTER, 1990).

As três vertentes delineadas tomam como ponto de partida as empresas e os empresários, desconsiderando o ambiente social, econômico e político no qual elas estão circunscritas. Não há referência ao modo capitalista de produção, à dimensão histórica das empresas e ao papel dos Estados. As grandes empresas surgem, literalmente, do nada ou, como preferem os gurus das business schools, como resultado das falhas de mercado e dos custos de transação.

Os avanços de empresas situadas em países periféricos têm sido compreendidos à luz dos arcabouços teóricos das vertentes teóricas delineadas, que têm limitações no plano teórico e na dimensão espacial e temporal, pois foram elaboradas para explicar a internacionalização de empresas localizadas em países desenvolvidos, cujos investimentos externos ocorreram desde finais do século XIX e mais intensamente a partir dos anos 1950.

Apesar desse predomínio, houve a elaboração de interpretações teóricas visando apreender as especificidades das empresas não sediadas em países desenvolvidos. A maior parte desses trabalhos teve como base aspectos microeconômicos, como: fatores de produção específicos no chão da fábrica, plantas com baixas economias de escala e adequadas às economias de igual ou menor nível desenvolvimento, fabricação de produtos relativamente homogêneos e maduros, baixos salários pagos aos trabalhadores e aos gerentes expatriados, adoção de tecnologia de produção adequada aos países menos desenvolvidos etc. (LECRAW, 1977; KUMAR, 1982; LALL, 1983).

Nos anos 1970 e 1980, essas variantes microeconômicas fundamentaram a definição de Multinacionais do Terceiro Mundo, que foi elaborada para elucidar as vantagens das empresas de países do Terceiro Mun- do em face a empresas de países desenvolvidos na concorrência por mercados em países de baixo nível de desenvolvimento. A definição de Empresas Multinacionais do Terceiro mundo foi elaborada para explicar os investimentos produtivos em países com níveis de desenvolvimento similares ou inferiores aos dos países periféricos.

Desde os anos 1980, porém, devido à adoção das diretrizes do "Consenso de Washington", novos elementos passaram a compor os mercados dos países periféricos. Muitos ramos foram concentrados e desnacionalizados e a concorrência extrapolou a escala nacional, atingindo as escalas regional e mundial. As empresas e grupos continuaram a investir em seu entorno, não somente pelas similitudes de desenvolvimento, como ainda pelas possibilidades abertas pelos blocos comerciais e pelas políticas de concessão e privatização (MIOTI; PERRIN; SACHWALD, 2001). Decerto, a principal mudança ocorreu com os investimentos em países desenvolvidos, à procura de mercado e de ativos importantes (tecnologia). O cenário emergente é de concorrência oligopólica e, dificilmente, os investimentos de empresas não sediadas nos países desenvolvidos podem ser avaliados sob as molduras da definição de Multinacionais do Terceiro Mundo.

A partir dos anos 1990, emergem novas interpretações teóricas acerca das empresas multinacionais não sediadas em países desenvolvidos. As proposições ajudam à compreensão da especificidade e complexidade da internacionalização do capital produtivo realizada por empresas da periferia. As novas contribuições são a articulação da multinacionalização de empresas aos níveis de desenvolvimento e à entrada e saída de IDE, a integração de empresas à economia global por meio de redes, os papéis institucionais exercidos pelos Estados (empréstimos, controle das empresas) e o desenvolvimento de competências estratégicas pelas empresas em ambientes turbulentos (DUNNING; HOESEL; NARULA, 1997; CHILD; RODRIGUES, 2005; MATHEWS, 2006; FLEURY; LEME FLEURY, 2006).

Apesar do avanço, as novas abordagens enfatizam apenas uma dimensão do fenômeno da multinacionalização, sem considerar a dimensão histórica, o ambiente social e econômico. É necessário, portanto, a articulação do avanço de empresas e grupos econômicos aos processos de acumulação, concentração e centralização do capital, no qual o Estado teve e tem um papel primordial (MICHALET, 1984). A acumulação de capital consiste num processo de reaplicação contínua do excedente extraído do trabalho no processo produtivo, tendo como finalidade última gerar, cada vez mais, um excedente sempre maior. Segundo Marx (1989, p. 
674), consiste na "aplicação de mais valia como capital ou conversão de mais valia em capital”. Há, portanto, uma reprodução do capital sempre em escala ampliada, com excedentes sendo reaplicados constantemente em novos meios de produção.

À medida que cada acumulação torna-se meio de uma nova acumulação, ocorre um aumento da concentração dos meios de produção e do comando correspondente sobre um exército menor ou maior de trabalhadores (MARX, 1989, p. 726). A premência pela acumulação constante pode ser compreendida por meio da modernização, da ampliação da escala de produção e do aumento do capital constante. O aumento do excedente e a sua concentração nas mãos do capitalista ocorrem, assim, mediante a ampliação da retirada de mais-valia absoluta e mais-valia relativa.

O processo concentração do capital é estorvado pela formação de novos e pela fragmentação de capitais existentes. A concentração crescente dos meios de produção e do comando sobre o trabalho é acompanhada pela repulsão recíproca de muitos capitalistas individuais. Essa repulsão é contrariada pela força de atração entre eles - a centralização de capital. Para Marx (1989, p. 727), a centralização consiste na concentração de capitais já formados, na expropriação do capitalista pelo capitalista e na transformação de capitais pequenos em grandes capitais.

A centralização de capital é um processo diferente da acumulação porque pressupõe apenas a alteração dos capitais já existentes e não está atrelado ao aumento da riqueza social e aos limites da acumulação. Embora a expansão relativa e a energia do movimento de centralização estejam ligadas à magnitude do estágio de desenvolvimento capitalista, o avanço da centralização independe do incremento positivo do capital social porque não ocorre apenas nas fases de expansão capitalista. As alavancas que garantem a centralização de capital são a concorrência capitalista e a disponibilidade de crédito (MARX, 1989, p. 727-728).

Os processos de acumulação, concentração e centralização do capital não estão circunscritos essencialmente às fronteiras nacionais, uma vez que o modo capitalista de produção, para sua reprodução, caracteriza-se pela necessidade crescente de novos mercados, de novos espaços de acumulação. Deste modo, a organização espacial e a expansão geográfica são essenciais à criação de oportunidades de acumulação de capital (HARVEY, 1975). A acumulação de capital, devido à sua condição existencial de constante valorização do capital individual, é essencialmente um processo que ocorre em escala mundial, sem obedecer aos limites políticos entre os Estados. A procura por novos espaços é uma condição subjacente à necessidade permanente de reinvestir a mais-valia social. Juntamente com a acumulação, a concentração de capital, mediante aumento do excedente em mãos de capitalistas individuais, exige crescentemente novos espaços.

Os agentes à frente da busca frenética pela valorização do capital são os grandes grupos econômicos, os quais são o resultado de um longo processo de concentração dos meios de produção e do controle sobre a mão de obra, bem como da centralização de capital (fusões e aquisições). A busca por novos espaços por esses grupos é indissociável das constrições locais à acumulação e do imperativo pela acumulação ampliada. Após a consolidação no país de origem, esses grupos lançam-se a novos espaços, onde promovem, continuamente, como exigência da acumulação, a concentração e a centralização de capital. O Grupo Votorantim, como qualquer outro grupo ou empresa, não foge à regra.

\section{O GRUPO VOTORANTIM: DA ORIGEM À CONSOLIDAÇÃO}

O Grupo Votorantim surgiu no ano de 1917, em plena Primeira Guerra Mundial, como uma empresa têxtil no Distrito Votorantim, Município de Sorocaba, no interior do Estado de São Paulo. A fábrica têxtil foi comprada, em sociedade, junto ao Banco União pelo imigrante português Antônio Pereira Inácio. Segundo Mamigonian (1976), Pereira Inácio adquiriu, com outros sócios, três tecelagens dos sucessores de L. Antonio Anhaia e D. Antonio de Barros e, por pouco mais de $10 \%$ de seu valor, a fábrica de tecidos Votorantim, valendo US\$ 10 milhões. Ao longo do tempo, Pereira Inácio assumiu o controle individual da fábrica e ascendeu à condição de um dos maiores industriais do Estado.

Antes de entrar na atividade têxtil, Pereira Inácio atuava na indústria de óleos vegetais no interior do Estado e na exploração de madeira. A acumulação de capitais nessas duas atividades foi importante para a mudança de foco com a compra da fábrica de tecidos em Sorocaba, junto a um banco em processo de falência, e da fábrica Lusitânia, localizada à época na cidade de São Paulo. Em pouco tempo, a fábrica de Sorocaba chegou a ser uma das maiores do país no setor têxtil, gerando mais de 5.000 postos de trabalho (BONELLI, 1998).

Em 1926, José Ermírio de Moraes se associou ao seu sogro, Antônio Pereira Inácio, para reestruturar a 
fábrica têxtil. Tinham como objetivo realizar lucros com a fábrica têxtil, mas foram surpreendidos pela depressão (crash) de 1929 e, consequentemente, pela eliminação da demanda estadunidense por produtos têxteis. Apesar das condições adversas, optaram por permanecer no negócio têxtil (SCANTIMBURGO, 1975).

A partir dos anos 1930, uma conjunção de fatores engendra um contexto favorável à diversificação dos negócios. Tanto a crise econômica mundial como a chegada ao poder de um governo cujas classes sociais eram favoráveis à industrialização contribuíram para o estímulo aos investimentos em indústrias inexistentes e atendidas pela importação. Houve um apoio incondicional do Estado, que agiu como um demiurgo, à instalação e à consolidação de indústrias de base, dentre elas cimento e aço. É nesse ambiente favorável que Antônio Pereira Ignácio e José Ermírio de Moraes promovem a diversificação dos seus negócios, direcionando investimentos para as indústrias de cimento, de aço, de química, de refratários, de filmes flexíveis. A ampliação do leque de atividades decorre não só do oportunismo, como ainda do apoio e das articulações existentes nas esferas do Estado, usufruindo de empréstimos subsidiados, da redução das tarifas de importação de máquinas e equipamentos, entre outros benefícios.

O apoio estatal incondicional à industrialização e as restrições às importações, sobretudo em decorrência das guerras mundiais, favoreceram a expansão e diversificação da indústria brasileira para suprir a demanda interna. Entre os anos de 1930 e 1970, ocorreu a consolidação de empresas brasileiras de "gestão familiar, algumas das quais pertencentes ao mesmo proprietário, constituindo conglomerados informais superdimensionados e diversificados setorialmente, por razões de dispersão do risco patrimonial" (MIRANDA; TAVARES, 2000, p. 330).

Entre os anos de 1930 e 1970, de forte apoio estatal, o Grupo Votorantim promoveu a consolidação dos negócios já existentes (concentração horizontal), a diversificação das atividades em ramos relacionados (concentração vertical) e em ramos não relacionados uns aos outros (concentração conglomeral). Deste modo, ainda nos anos 1930, não só deu continuidade ao avanço em cimento, como ainda ingressou nas atividades química e siderúrgica. Nos anos 1940, investiu em refratários, em bens de capital e na exploração mineral. Nos anos 1950, avançou para negócios de papel, de cal, de açúcar e álcool e de metais. Nos anos 1960, expandiu a atuação para exploração de metais e produção de cerâmica. Nos anos 1970, em função do II Plano Nacional de Desenvolvimento (PND), em vez de dar continuidade à diversificação, promoveu o fortalecimento e consolidação das indústrias de base, particularmente cimento, química, siderurgia e bens de capital.

Por mais de 40 anos, a diversificação e consolidação do grupo ocorreu, prevalentemente, sob a forma de concentração de capital, quer dizer, investimentos na construção de novos estabelecimentos produtivos e na ampliação da capacidade produtiva das unidades já existentes. Isso não significa que não houve centralização de capital, com a aquisição de concorrentes no ramo de atuação e de empresas atuantes em negócios escolhidos para diversificação. Historicamente, como imperativo pela acumulação de capital e devido à luta intercapitalista pela concentração da oferta, o conglomerado optou mais por investimentos novos do que por aquisições e fusões.

Desde os anos 1980, porém, diante da crise da dívida externa, o Estado deixou de ser o demiurgo na promoção da atividade industrial. Em meio à crise, muitos grupos quebraram, direcionaram seus investimentos, foram adquiridos, fortaleceram operações rentistas etc. O Grupo Votorantim, comandado pela segunda geração, continuou a diversificar os negócios e a promover uma consolidação na escala nacional, principalmente em cimento.

É nos anos 1980 que a terceira geração da família Moraes assume a frente dos negócios do grupo. Os novos gestores continuaram a diversificação com o ingresso nas atividades de suco concentrado de laranja, de biotecnologia, de tecnologias da informação e finanças. A dimensão espacial de atuação extrapolou as fronteiras nacionais, mediante a abertura de mercados para as exportações no exterior (criação de escritórios comerciais). O avanço no exterior ocorreu, inicialmente, pela via comercial, em negócios ancorados em recursos naturais (papel e celulose, suco concentrado de laranja, nitrocelulose).

A dimensão macroeconômica prevalente da terceira geração de gestores tem sido diferente da dos anteriores, que contaram com a ajuda do Estado e com o movimento de concentração de capital. Desde os anos 1990, as condições são outras, marcadas pelo acirramento da concorrência oligopólica na escala mundial. A abertura econômica acelerada/indiscriminada e o capital em seu movimento de centralização forçaram os novos gestores a reestruturar os negócios, isto é, fortalecer os ramos em que o grupo era competitivo e vender as atividades consideradas não estratégicas, como têxtil, filmes flexíveis, energia, biotecnologia.

Os core business escolhidos pela terceira geração são cimento, metais, agronegócio, papel e celulose, finanças e novos negócios. Em zinco e em cimento, 
ramos nos quais é líder nacional, o movimento é de concentração da oferta em escala mundial por uma dúzia de grandes produtores; a atuação do grupo, portanto, extrapolou o espaço nacional, devido a sua participação no processo de centralização de capital mundial. Em papel e celulose, novos negócios e finanças a estratégia levada a cabo tem sido de consolidação nacional.

As grandes unidades de negócios do grupo são compostas por inúmeras empresas, de diversos ramos, espalhadas pelo Brasil e em 12 países, totalizando 65 mil trabalhadores. Contudo, a complexidade e o poder econômico do grupo precisam ser compreendidos à luz de da concentração dos meios de produção e comando de um contingente significativo de mão de obra, processo delineado por meio de ampliação da mais-valia posta num círculo virtuoso de valorização, e da centralização de capital.

Atualmente, o conglomerado é o $5^{\circ}$ maior do país, com receitas superiores a $\mathrm{R} \$ 30$ bilhões. $\mathrm{O}$ detalhamento por negócios permite constatações importantes. Em cimento, é o maior do país, com $40 \%$ do mercado, e o $7^{\circ}$ produtor mundial. Em zinco, detém $100 \%$ do mercado interno e é $3^{\circ}$ maior no mundo. Em níquel, controla mais da metade do mercado interno. Em papel e celulose, é o maior produtor nacional e mundial de celulose de eucalipto. É o $3^{\circ}$ maior produtor mundial de suco concentrado de laranja. A atuação é menos importante apenas em finanças e em siderurgia. Esse parágrafo não deve ser lido com saudosismo, mas como o resultado de uma concentração e centralização de capital ao longo do tempo, em que o papel do Estado e a postura conservadora dos dirigentes do grupo culminaram no controle de negócios que são, na sua maior parte, de baixo conteúdo tecnológico e na adoção de práticas de preços danosos à sociedade.

O grupo possui um caráter multifuncional por atuar em diferentes ramos, como cimento e agregados, siderurgia, bens de capital, energia, banco, exploração mineral, papel e celulose, biotecnologia etc. Isso se deu, historicamente, por meio das concentrações horizontal, vertical e conglomeral. A diversificação resultou na segmentação, pois as atividades são diferentes quanto aos níveis de desenvolvimento tecnológico, à divisão territorial do trabalho e ao papel que desempenham no grupo. Quanto à tecnologia, atuação abarca desde atividades cuja tecnologia é madura (cimento, aço, alumínio, papel e celulose) até aquelas situadas na vanguarda tecnológica (tecnologia da informação). A complexa divisão territorial do trabalho resulta das diversas localizações e interações entre as várias unidades de negócios espaIhadas pelo Brasil e pelos países onde possui unidades produtivas e escritórios comerciais.
A integração territorial da gestão é exercida pela holding Votorantim Participações, que desempenha um papel importante sobre a decisão nas formas de geração de valor (industrial e financeiro). A integração territorial da produção é entendida como as interações entre os diversos negócios de um grupo, como matériasprimas, unidades fabris, atividades para frente e para trás, finanças etc. (CORRÊA, 1992). Essas articulações entre as unidades do grupo, formando várias redes, estão presentes na atividade de cimento (jazidas - fábricas de cimento - empresas de concreto), em química (minérios - indústria química), em papel e celulose (reflorestamento - fábricas), em bens de capital (demais fábricas - hidrelétricas - fábrica de alumínio).

No processo de acumulação de capital, as decisões do grupo engendram interações espaciais complexas que podem ser compreendidas, em muitos casos, apenas hipoteticamente, haja vista a dificuldade de esboçar todas as relações. Inegavelmente, essas interações espaciais decorrentes do processo de acumulação levado a cabo pelo grupo tornam-se mais complexas com a internacionalização comercial e produtiva. Os investimentos e os fluxos externos, além da força de trabalho e das matérias-primas, são realizados em função das diferenças cambiais, do acesso a capitais e a juros mais baixos, dos fluxos intragrupo etc.

\section{A INTERNACIONALIZAÇÃO PRODUTIVA DO GRUPO VOTORANTIM}

O Grupo Votorantim, pelos ramos de atuação, esteve voltado, desde o início, ao mercado interno, devido ao reduzido comércio internacional de cimento em relação à produção total. Os fluxos reduzidos do produto resultam de seu baixo valor agregado e de sua perecibilidade. Ramos como o metalúrgico, o siderúrgico e o de refratários, por sua vez, foram marcados pela integração vertical dentro das operações do conglomerado e pela demanda crescente do mercado interno. $O$ negócio direcionado aos mercados interno e externo foi o de química, com a exportação de nitrocelulose. Posteriormente, com a diversificação das atividades, ramos como metais, celulose e papel e suco concentrado de laranja também foram direcionados para atender a demanda do mercado internacional.

A fim de intensificar as exportações, reduzir os custos e a dependência de terceiros, facilitar as importações etc., o grupo criou uma trading company, a Votorantim Internacional, em 1991. A companhia foi criada para 
ser o braço direito das operações de suco concentrado de laranja e de papel e celulose no exterior, mediante a abertura de escritórios comerciais em Hamburgo e Antuérpia, na Europa, em Newark e Baltimore, na América do Norte, em Cingapura, na Ásia, e em Newcastle, na Oceania. Coube aos escritórios auxiliar na prestação de serviços financeiros, fiscais, administrativos e logístico e proporcionar a redução dos custos (seguros e fretes) de importação e de exportação.

Os investimentos produtivos externos remontam ao início deste século, com a aquisição de empresas nos Estados Unidos, no Canadá, no Peru, na Argentina, entre outros países. Temporalmente, os investimentos no exterior foram direcionados às aquisições no ramo de cimento, na exploração e refino de zinco e em siderurgia.

\section{CIMENTO}

O primeiro investimento produtivo no exterior do grupo data de 2001, quando adquiriu a empresa canadense Saint Mary's, por US\$720 milhões. Dois anos depois, adquiriu $50 \%$ da empresa estadunidense Suwanee American Cement, em Branford, Estado da Flórida, por US\$100 milhões, do grupo Anderson Columbia. Ainda em 2003, comprou uma empresa de moagem de cimento, a Badger Cements Products, situada em Milwaukee, Estado de Wisconsin, Estados Unidos.

Visando agregar valor à produção de cimento na Flórida, o grupo adquiriu a empresa de concreto S\&W Materials, de faturamento superior a US\$20 milhões, responsável por $14 \%$ do mercado de concreto da Flórida. Essa aquisição demonstra a estratégia de integração vertical das atividades nos Estados Unidos, com o controle de toda a cadeia produtiva do cimento.

No ano de 2005, adquiriu alguns ativos da terceira maior produtora de cimento mundial, a mexicana Cemex. Os US\$ 400 milhões envolvidos no negócio foram por 2 fábricas de cimento (em Charlevoix, Estado de Michigan, e em Dixon-Marquette, Estado de Illinois), com capacidade de produção de 2 milhões de toneladas de cimento, 8 terminais e 2 navios de transporte de cimento. Esses ativos estão situados no nordeste dos Estados Unidos e próximos dos que foram adquiridos no Canadá. Deste modo, os ativos foram adquiridos com uma estratégia de serem integrados para o fornecimento de cimento, concreto e agregados ao maior mercado consumidor na América do Norte.

Em 2007, comprou a empresa estadunidense de concreto Prestigie, por US\$200 milhões. Um ano depois, adquiriu a décima maior empresa de concreto nos Estados Unidos, a Prairie, por valores estimados

entre US\$ 400 e 500 milhões. A Prairie, sediada em Chicago, atua nos Estados de Illinois, Indiana, Michigan e Wisconsin. A aquisição permitiu ao grupo somar mais 81 centrais de concreto, 17 minas de agregados, depósitos e caminhões de transporte de materiais aos seus ativos no mercado estadunidense.

As aquisições das empresas concreteiras Prestigie e Prairie, de atuação, respectivamente, na Flórida e nos Grandes Lagos, fazem parte da estratégia do grupo de fortalecer sua atuação em toda a cadeia produtiva de cimento, mediante a compra de empresas clientes de suas fábricas, denotando uma busca pela integração vertical e pelo controle de toda a cadeia de valor da indústria da construção. Com as duas transações, o grupo dobrou de tamanho nos Estados Unidos, elevando o seu faturamento para valores próximos a US $\$ 1,5$ bilhão.

Em 2008, o grupo adquiriu $15,2 \%$ da Cementos Bío Bío S.A., do Chile, por mais US\$100 milhões. O Grupo Bío Bío atua nos ramos de cimento, concreto e cerâmica e possui faturamento superior a US\$ 680 milhões por ano, com suas unidades produtivas de cimento, de cal e de concreto espalhadas pelo Chile e de cerâmica, no Chile, no Peru, na Venezuela, no Equador e nos Estados Unidos.

Com as aquisições, o grupo passou a deter, em 5 países americanos, 39 fábricas de cimento (incluindo as de moagem e as que estão em fase final de construção), mais de 50 centros de distribuição e uma centena de cidades atendidas pela oferta de concreto e agregados, cuja dificuldade de mapeamento é enorme, porque as empresas de concreto atendem, geralmente, vários municípios (mapa 1). 


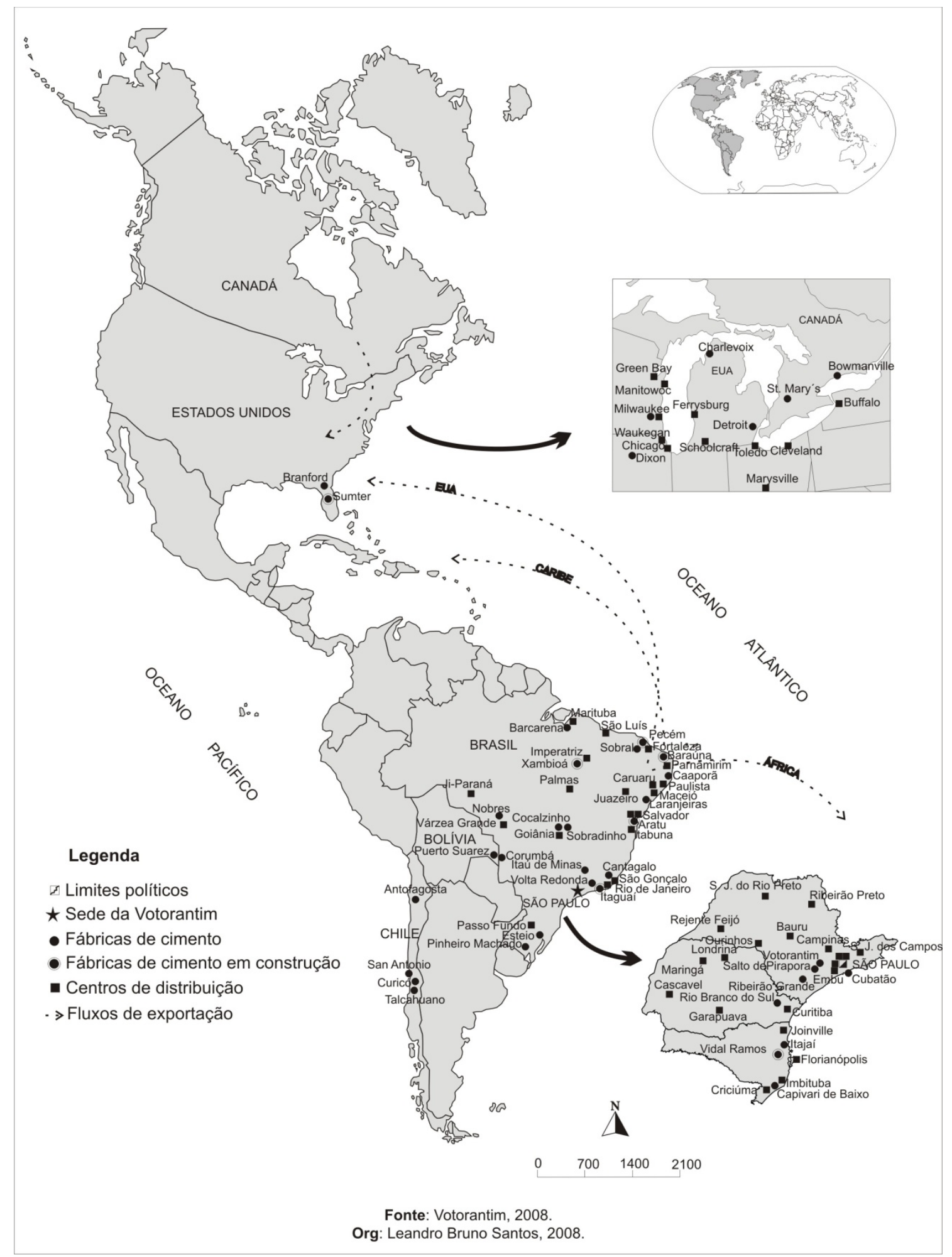

MAPA 1 - LOCALIZAÇÃO DOS ATIVOS EM CIMENTO DO GRUPO VOTORANTIM 
Com os ativos situados no nordeste dos Estados Unidos e no sudeste do Canadá, o Grupo tem lançado mãos de duas estratégias. Primeiro, tem otimizado seus estabelecimentos produtivos na principal região consumidora de cimento e subprodutos nos Estados Unidos.
Segundo, tem exportado cimento da Região Nordeste do Brasil para os Estados Unidos, maior importador mundial do produto, mediante fluxos entre empresas do próprio grupo.

\section{ZINCO}

O segundo ramo escolhido pelo conglomerado para a realização de investimentos no exterior é o da exploração e refino de zinco, metal utilizado, principalmente, na galvanização por indústrias siderúrgicas para proteger o aço da corrosão. Com a demanda mundial em alta por causa da demanda da China, os preços de zinco sofreram uma escalada significativa, o que explica, evidentemente, o avanço do conglomerado para mercados cujas reservas e produções anuais de zinco são elevadas, especialmente China, Estados Unidos e Peru.

Os primeiros investimentos realizados pelo Votorantim na exploração de zinco datam da década de 1960. Porém, os investimentos significativos nessa atividade são do início deste século, a partir da aquisição da Companhia Paraibuna de Metais, em 2002. Dois anos depois, fez a primeira aquisição internacional, mediante a compra da Companhia de Zinco de Cajamarquilla, por cerca de US\$ 210 milhões. A companhia adquirida está situada no Peru, país que tem reservas estimadas em 20 milhões de toneladas do metal (NEVES, 2007).

Em 2005, um ano após a aquisição da Cajamarquilla, o grupo comprou participação acionária significativa na empresa peruana de mineração Milpo, cuja atuação é na exploração de zinco, de chumbo e de Cobre, a partir de três jazidas situadas no Peru (Cerro Lindo, El Porvenir e Chapi) e uma localizada no Chile (Iván). Por cerca de $25 \%$ das ações da Milpo, o grupo desembolsou o equivalente a US\$100 milhões. Neste ano, o Votorantim fez duas ofertas para obter cerca de $26 \%$ das ações da mineradora na bolsa de valores do Peru, com o objetivo de deter mais da metade das ações, mas teve as suas propostas rejeitadas.

Além da forte demanda da China, causando a monetização do metal, o avanço do Grupo Votorantim no Peru, por meio de sua unidade de negócios de metais, pode ser explicado pela busca do grupo em adquirir os seus maiores fornecedores, quer dizer, verticalizar os seus negócios em zinco. O Brasil depende, ainda, da importação de zinco e a maior parte da aquisição externa é proveniente do Peru, país detentor de amplas reservas mundiais do metal.

Em 2007, o Votorantim promoveu a maior aquisição de sua história em Zinco, ao comprar a empresa estadunidense US Zinc, por US\$ 295 milhões. A aquisição foi estratégica porque permitiu ao grupo ingressar nos dois maiores mercados consumidores do produto e maiores detentores de reservas confirmadas do metal. Foram acrescentadas, assim, cinco unidades produtivas nos Estados Unidos e uma em fase final de construção na China. Atualmente, cerca de $40 \%$ das receitas em zinco, após as aquisições, correspondem às unidades internacionais.

Os ativos do grupo em zinco, após essa última aquisição, são 7 refinarias de zinco, 4 escritórios de vendas e 3 jazidas do metal, dispostos pela América (Brasil, Estados Unidos, Peru) e pela Ásia (China) (mapa 2). 


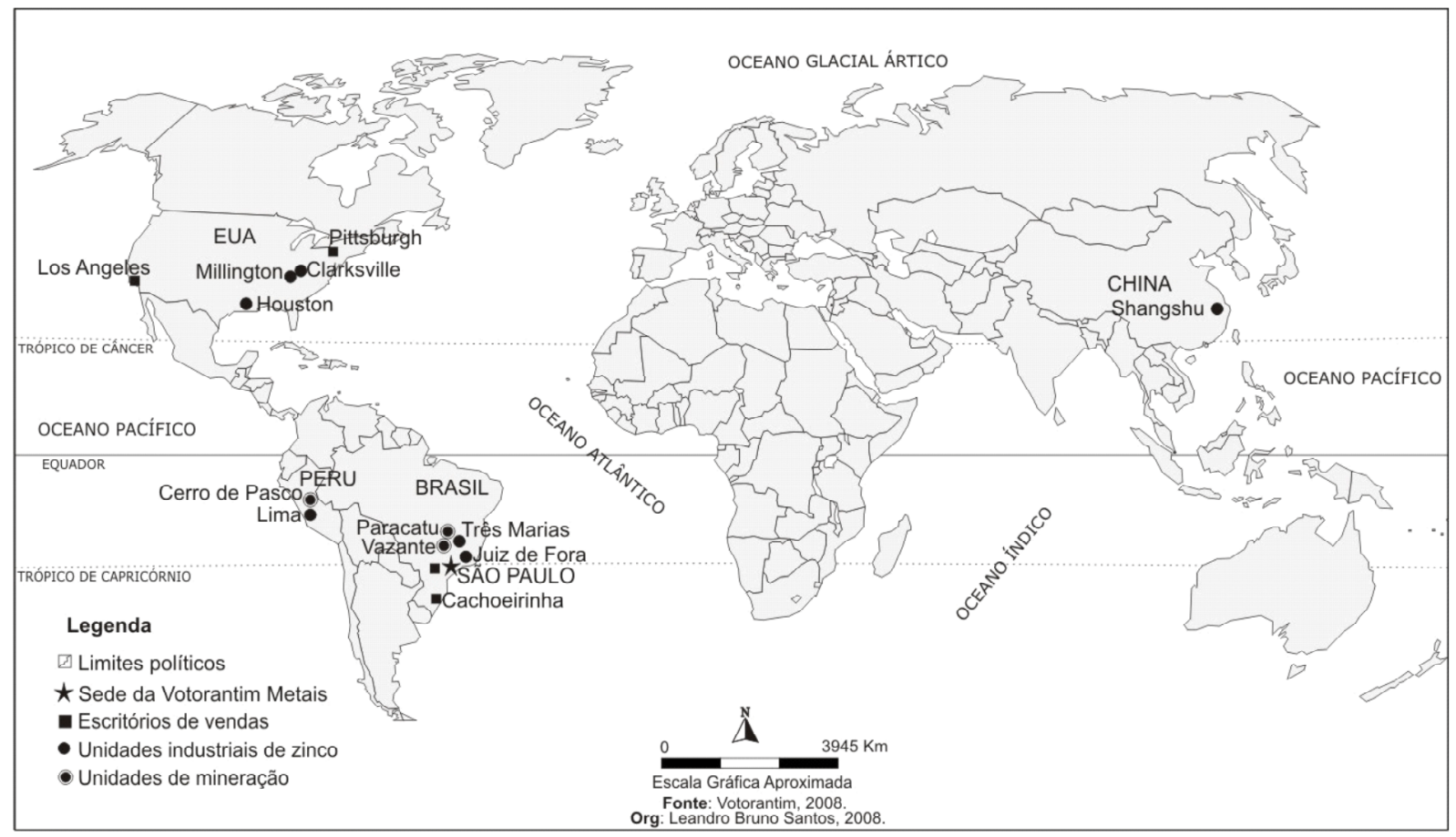

MAPA 2 - LOCALIZAÇÃO DOS ATIVOS EM ZINCO DO GRUPO VOTORANTIM

Com a aquisição da US Zinc, o grupo passou a deter unidades produtivas nos dois maiores mercados consumidores de zinco no mundo (sendo 1,2 milhões de toneladas nos Estados Unidos e 3,5 milhões de toneladas na China). Além disso, a aquisição permitiu ao grupo elevar a sua capacidade de produção de 430 mil toneladas para 590 mil toneladas (incluindo a unidade em construção na China) e tornar-se o terceiro maior no segmento de zinco no mundo (atrás apenas da empresa estadunidense NY Star e da sul-coreana Korea Zinc) e o primeiro em óxido de zinco.

\section{SIDERURGIA}

Depois de avançar em cimento e em zinco, os investimentos externos mais recentes têm sido em siderurgia. A demanda mundial por aço tem crescido bastante nos últimos anos, devido, sobretudo, ao surpreendente avanço da China. No Brasil, houve também o aumento da demanda doméstica por aço por causa do crescimento da economia, com maior consumo na construção civil e na indústria automobilística. Esse crescimento da demanda interna, inclusive, fez com que houvesse uma redução das exportações brasileiras, pois as siderúrgicas aqui instaladas foram forçadas a despachar os produtos siderúrgicos para abastecer a demanda crescente do mercado interno.
Esse crescimento da demanda interna, puxada pelo crescimento econômico, já é acompanhado de projetos de expansão de capacidade produtiva de unidades existentes e de construção de novas unidades, especialmente pela Usiminas. O Grupo Votorantim, além de ampliar a capacidade produtiva de sua unidade siderúrgica de Barra Mansa para 700 mil toneladas, está investindo R\$ 1 bilhão na construção de uma fábrica com capacidade de produção de 1 milhão de toneladas de aços longos no Município de Resende, Estado do Rio de Janeiro.

Os investimentos externos do grupo no ramo siderúrgico foram direcionados a países situados na 
América. Os IDE externos destinaram-se à aquisição de ativos importantes de empresas na Colômbia e na Argentina. A primeira aquisição internacional ocorreu em 2007, a partir da compra de $52 \%$ do capital da siderúrgica Acerías Paz del Río S.A., situada em Boyacá, Colômbia, por US\$ 491 milhões. O leilão das ações da empresa colombiana contou, também, com a participação de dois dos maiores produtores mundiais, o Arcelor Mittal e o Gerdau, o que elevou o valor inicial da companhia que era de US\$193,4 milhões.

A compra permitiu ao grupo acrescentar aos seus ativos já existentes uma unidade industrial com capacidade de produção de 450 mil toneladas de aço por ano e faturamento superior a US\$170 milhões. Os ativos da empresa adquirida vêm ao encontro do que é praticado pelo grupo no mercado interno, pois as jazidas de minério de ferro, de carvão mineral e de calcário são integradas, permitindo não só sinergias, como também a integração vertical, de modo a não depender de terceiros e das oscilações de mercado.

Um ano após a aquisição da maior parte das ações da companhia siderúrgica Acerías Paz del Río S.A., segunda maior do ramo na Colômbia, o grupo, por meio de sua divisão de metais, eleva sua participação na empresa ao comprar as ações sob o controle do Grupo Gerdau, de 9,9\%, por US\$63,3 milhões. Ao todo, o Votorantim desembolsou cerca de US\$554,3 milhões por $61,9 \%$ das ações da empresa colombiana.

Em 2008, passou a fazer parte do bloco de controle da segunda maior produtora de aços longos da Argentina, depois da aquisição de $27 \%$ da empresa AcerBrag, pelo valor de US\$ 60 milhões. Logo após a compra, o grupo elevou sua participação para $52,9 \%$ do capital da empresa, adquirindo, assim, o seu controle efetivo com a maior parte das ações. Para a aquisição do controle da siderúrgica argentina o grupo desembolsou valores próximos a US\$120 milhões.
Com o controle da nova empresa, foram acrescentados à produção e às receitas, respectivamente, 250 mil toneladas de aço por ano e faturamento superior a US\$130 milhões. Deste modo, o Grupo Votorantim, com as duas empresas siderúrgicas adquiridas, passa a deter, no exterior, capacidade produtiva superior a 700 mil toneladas e receitas de US\$ 300 milhões. As possibilidades de expansão no mercado interno, por meio de aquisições, são reduzidas, porque já houve a concentração da oferta durante os anos 1990 e o grupo não participou.

Atualmente, as possibilidades de crescimento dos negócios em siderurgia existentes são duas: i) expandir por meio de aquisições externas, como forma de acompanhar o movimento de concentração da oferta em escala mundial; ii) aproveitar as condições econômicas positivas no mercado interno, visando à elevação da capacidade de produção por meio da modernização de unidade fabril ou da construção de novas unidades. Esta última proporciona, logicamente, uma possibilidade menor de crescimento face às aquisições, pois os tempos de maturação dos investimentos e de crescimento da participação no mercado são elevados. A maneira mais rápida de crescimento é a centralização de capital, estratégia que é possível apenas nas escalas regional e mundial, pois o mercado interno já foi concentrado pelos maiores produtores mundiais.

Somadas as duas empresas adquiridas e as duas usinas no Brasil, a capacidade de produção subiu de 700 mil toneladas para mais de 2,4 milhões de toneladas, ou seja, houve uma elevação de mais de 3 vezes. Além disso, o grupo possui parcela importante de ações (13\%) no controle da Usiminas, juntamente com Camargo Corrêa (13\%), Nippon Steel $(27,8 \%)$, Previ $(10,4 \%)$ e Caixa dos empregados da Usiminas $(10,1 \%)$ (mapa 3). 


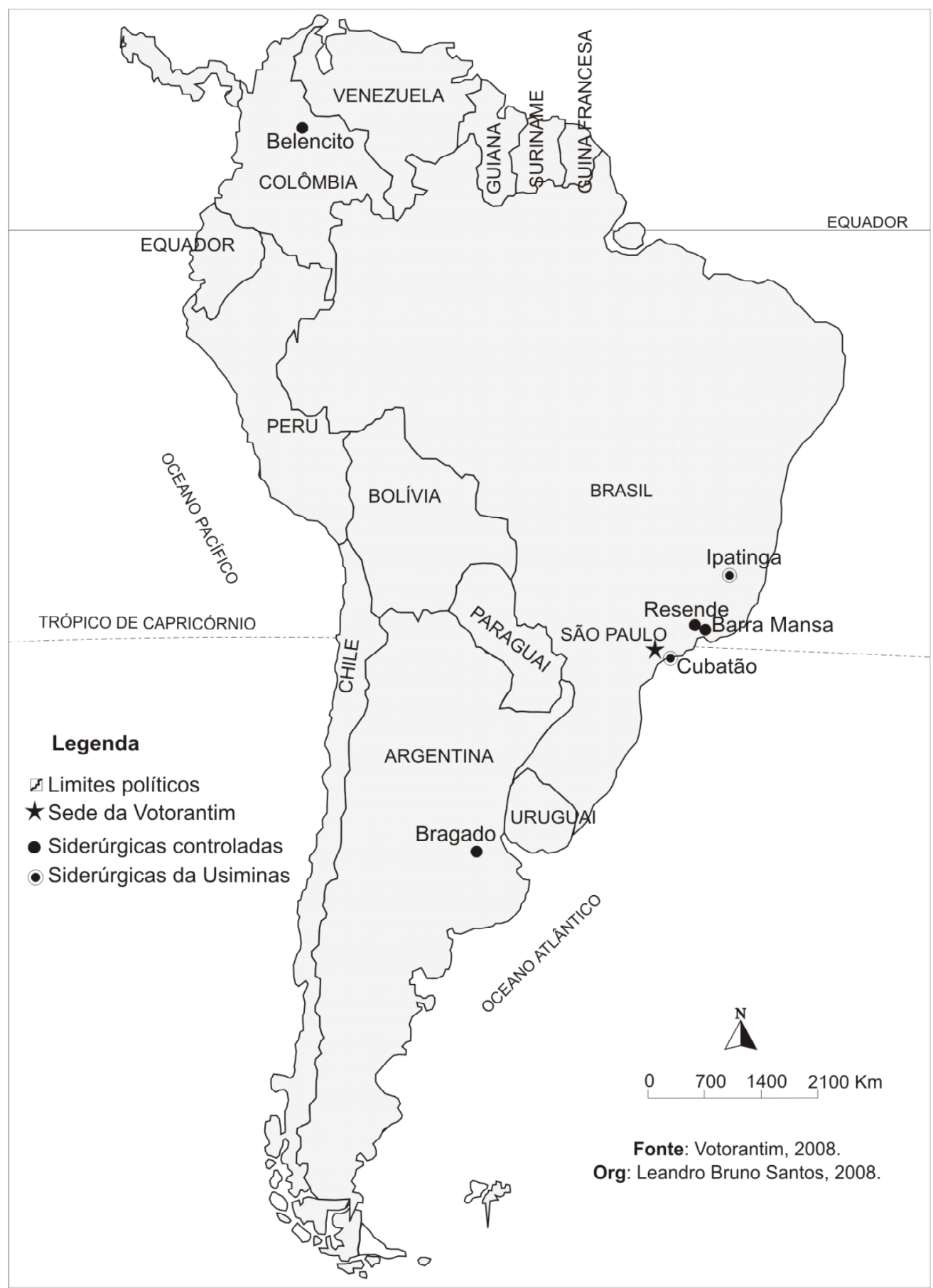

MAPA 3 - LOCALIZAÇÃO GEOGRÁFICA DOS ATIVOS EM SIDERURGIA DO GRUPO VOTORANTIM²

2 O Grupo detém participação acionária relevante no bloco de controle da Usiminas. 
Além das aquisições, o grupo possui investimentos em novas unidades fabris nos Estados Unidos e no Peru que somam quase US\$ 1 bilhão (tabela 1). Os investimentos estão sendo destinados à ampliação da produção de cimento e de zinco.

TABELA 1 - INVESTIMENTOS GREENFIELDS DO VOTORANTIM NO EXTERIOR, EM US\$ MILHÕES

\begin{tabular}{|c|c|c|c|c|}
\hline Empresa & País & Setor & Valor & Ano \\
\hline $\begin{array}{l}\text { Cajamarquilla } \\
\text { St. Mary's }\end{array}$ & $\begin{array}{c}\text { Peru } \\
\text { Estados Unidos }\end{array}$ & $\begin{array}{c}\text { Zinco } \\
\text { Cimento }\end{array}$ & $\begin{array}{l}500 \\
400\end{array}$ & $\begin{array}{l}2007 \\
2007\end{array}$ \\
\hline
\end{tabular}

Fonte: Grupo Votorantim, 2008.

Org: Leandro Bruno Santos, 2008.

Em 2008, foram anunciados investimentos de US\$ 1,5 bilhão na Colômbia, no ramo siderúrgico. Os investimentos fazem parte de um acordo do Votorantim, em parceria com o Grupo Acerías de Colombia (Acesco), para a construção de uma usina siderúrgica, na Cidade de Barranquila, que terá capacidade de produção de 1,4 milhões de toneladas de aços planos por ano e irá atender os mercados colombiano, caribenho e estadunidense. A participação acionária de cada grupo no empreendimento, porém, não foi divulgada.

Os valores envolvidos na multinacionalização do Votorantim, contabilizando as aquisições, as joint ventures e os investimentos em novos estabelecimentos produtivos, são da ordem de US $\$ 4.2$ bilhões. O ramo de cimento foi o que mais recebeu investimentos no exterior, seguido por zinco e por aço. Somente o ramo de cimento foi responsável por mais da metade de todos os investimentos (58\%), zinco por um quarto $(25 \%)$ e aço por $15 \%$.

Os investimentos foram levados a cabo, inicialmente, sob a forma de aquisições de ativos estrangeiros. Essa estratégia de inserção produtiva no exterior prevalece sobre as fusões, sobre os investimentos em novas plantas e sobre as joint ventures. A aquisição de ativos não representa apenas a corrida pelo controle da oferta oligopólica mundial, senão também a possibilidade de as empresas e grupos conseguirem um crescimento externo rápido, com a procura por ativos com parcelas de mercado e know how significativos.

Dos US $\$ 4.2$ bilhões destinados à internacionalização produtiva, cerca de US\$ 2.9 bilhões $(69,4 \%)$ envolveram a aquisição de ativos, US $\$ 800$ milhões $(21 \%)$ investimentos novos, US\$300 milhões $(7,3 \%)$ participação acionária em outras empresas e US\$ 200 milhões $(2,3 \%)$ parcerias. A estratégia de aquisição é uma boa oportunidade para as empresas que têm pretensões de investir no exterior e de conseguir uma parcela importante do mercado. Com o passar do tempo, os investimentos passam a ser na forma de investimentos novos.

As estratégias de investimentos produtivos levadas a cabo são birregionais, pois envolvem duas regiões bem distintas quanto ao desenvolvimento econômico e à cultura. A criação de valor pelo grupo ocorre tanto em países desenvolvidos como em países periféricos redefine as relações Sul-Sul e relativiza as relações Norte-Sul. Se até os anos 1980 a concentração e centralização de capital na escala mundial estavam restritas às empresas da tríade, o avanço do Votorantim e demais empresas situadas nos países periféricos, principalmente a partir dos anos 1990, sinalizam um processo de centralização descentrada do capital, isto é, não há um único centro polarizador da centralização.

As estratégias espaciais de acumulação por detrás dos investimentos externos do conglomerado se alteram de um país a outro. Nos Estados Unidos e Canadá, a procura é por ativos estratégicos e por mercado consumidor, enquanto no Peru a busca é por recursos naturais. A entrada na Colômbia, na Argentina e no Chile deve-se ao rápido crescimento econômico desses países nos últimos anos. 


\section{OS MOTIVOS DA EXPANSÃO INTERNACIONAL DO GRUPO}

As causadas da internacionalização se alteram de acordo com os ramos escolhidos pelo Votorantim. Em certos negócios, vários são os motivos destacados pelo conglomerado. Seguem, abaixo, uma síntese dos motivos impulsionadores:

\section{A) ESTAGNAÇÃO DO MERCADO INTERNO E DIVERSIFICAÇÃO GEOGRÁFICA DOS MERCADOS}

A indústria de cimento, no Brasil, está ligada indissociavelmente à política macroeconômica, porque depende sensivelmente da geração de emprego e do crescimento econômico. Quando a economia cresce e aumenta o número de pessoas admitidas no mercado de trabalho, aumenta o consumo de cimento dos consumidores "formigas", ao passo que, nos momentos de baixa dinamicidade econômica e aumento do desemprego, ocorre a queda no consumo de cimento.

Ao mesmo tempo, investir em outros mercados é uma alternativa de diversificação importante devido aos diferentes ciclos da construção em cada economia. Antes de estourar a atual crise financeira, os Estados Unidos conheciam um boom no mercado imobiliário e o Brasil, uma estagnação no consumo de materiais de construção. Desde 2008, porém, em função da crise financeira, diminui sensivelmente a demanda por cimento nos Estados Unidos, enquanto o mercado brasileiro ficou aquecido.

É relevante, ainda, chamar a atenção ao fato que mais importante que diversificar os riscos é preciso escolher os novos espaços de acumulação, e a escolha dos Estados Unidos e do Canadá é porque a cadeia de valor do cimento é integrada e porque os ativos adquiridos estavam localizados próximos aos Grandes Lagos, onde se concentra os maiores centros urbanos dos Estados Unidos.

\section{B) REAÇÃO OLIGOPÓLICA AO COMPORTAMENTO DOS LÍDERES}

O avanço em cimento pode, também, ser compreendido como uma resposta aos movimentos de concentração da oferta na escala mundial. Desde os anos 1970, após consolidação e concentração do ramo na Europa, os principais produtores, Lafarge e Holcim, buscaram por ativos na America Latina. A crise dos anos 1980, porém, obrigou-os a buscar pela concentração oligopólica na Ásia, cujo crescimento foi contínuo durante essa década. Nos anos 1990, a estabilização econômica na América Latina atraiu, novamente, os maiores produtores mundiais sedentos pela concentração e centralização de capital. O avanço do Votorantim no exterior está ligado às ações dos maiores produtores mundiais e à redução dos ativos disponíveis no continente americano. Em vez de uma concorrência pura e perfeita, com uma miríade de participantes, os mercados são, na maior parte, oligopolizados e as ações e estratégias são levadas a cabo em função, às vezes, da antecipação de um concorrente.

\section{C) MONETIZAÇÃO DOS RECURSOS NATURAIS}

Em função do crescimento acelerado da China nos últimos anos, a demanda por recursos naturais aumentou consideravelmente. Os minerais utilizados na siderurgia tiveram a maior elevação, principalmente minério de ferro e zinco. Este último metal teve uma valorização de quase quatro vezes nos últimos anos, pois o preço da tonelada subiu de US $\$ 1.381,76$, em 2000, para US $\$ 4.403,63$, no final de 2006.

A valorização do zinco é, sem dúvida, um fator importante que ajuda a explicar o avanço do Votorantim no exterior. A expansão não foi aleatória, porque respondeu a alguns objetivos espaciais estratégicos: i) a escolha pelos maiores mercados consumidores de zinco no mundo (Estados Unidos e China) e pelos países onde há as maiores reservas do metal (China, Estados Unidos e Peru); ii) aquisição de empresas fornecedoras de zinco para suas unidades, o que demonstra a sua estratégia de integração vertical, redução dos riscos e busca por maior rentabilidade.

\section{D) OPORTUNIDADES DE CRESCIMENTO}

Em siderurgia, o grupo aproveitou as oportunidades externas existentes, pois existem limitações de crescimento no mercado interno. No Brasil, detém uma fábrica em funcionamento e uma em construção. 
Detém, ainda, uma participação acionária na Usiminas, principal siderúrgica nacional. O ramo siderúrgico tem sido alvo de constantes fusões e aquisições nos últimos anos, denotando, assim, a centralização e concentração de capital em escala mundial. Quem não aproveitar o momento de consolidação para crescer, certamente estará fora do tabuleiro da competição mundial e restará a aliança com um grande produtor mundial ou a venda dos ativos.

João Bosco Silva, diretor-superintendente da Votorantim Metais, sobre a Acer Brag, segunda empresa que mais produz aços longos na Argentina na qual a Votorantim tem participação $27 \%$, afirma que

a alta concentração e volatilidade do setor do aço, que atravessa uma onda de fusões, aquisições e acordos estratégicos, levou os acionistas a realizar ações que permitirão explorar com melhores possibilidades o bom momento que vive o setor ${ }^{3}$.

Portanto, devido às possibilidades no mercado interno reduzidas, por causa da concentração já levada a cabo nos anos 1990 e da ausência do Votorantim, a saída tem sido a aquisição de ativos no exterior.

\section{E) ACESSO A CAPITAIS BARATOS}

Os investimentos também foram justificados pela necessidade de contornar o custo Brasil, onde o acesso ao mercado de capitais é muito oneroso. As empresas controladas pelo Votorantim nos Estados Unidos têm acesso a financiamento a juros baixos nas mesmas condições que os seus concorrentes mundiais. Por meio dessas empresas, o grupo tem transferido, para o Brasil, recursos para financiar a sua expansão. As escalas nacional, regional e mundial mais do que um recurso analítico, se interpenetram na acumulação e na produção do espaço, com a incorporação de características de uma escala pela outra.

Deste modo, as desigualdades dos fatores de produção estão sendo contornadas pelas empresas e grupos brasileiros por meio do investimento direto nos países desenvolvidos, onde as taxas de juros são baixas em face às cobradas internamente. Curiosamente, as mesmas empresas que reclamam dos juros escorchantes e da valorização cambial, também detêm títulos da dívida pública a juros altos e títulos de derivativos cambiais a favor e contra a valorização da moeda brasileira.

\section{F) AUMENTO DAS RECEITAS EM MOEDAS FORTES}

Desde os anos 1990, o Real passou por vários momentos de valorização e desvalorização que tiveram impactos nas empresas exportadoras, cujas receitas tendem a variar entre trimestres e anos. As empresas exportadoras não só perdem receitas, como ainda veem a competitividade cair diante de concorrentes externos. Deste modo, as diretrizes estratégicas adotadas pelos gestores à frente do Votorantim visam protegê-lo das oscilações inesperadas no preço do dólar. Atualmente, cerca de $30 \%$ das receitas são de moeda estrangeira e o objetivo é alcançar $50 \%$. Cerca de $15 \%$ das receitas em moeda estrangeira são provenientes de exportações e os outros $15 \%$ de unidades produtivas controladas em outros países.

Essa proteção da variação cambial, porém, extrapola a esfera da circulação e da produção de mercadorias. O grupo tem atuado, também, no mercado de derivativos de câmbio futuros, com o fito de se proteger das variações positivas do Real. Se a moeda brasileira dá sinais de valorização face ao dólar, o grupo age no mercado de câmbio apostando na valorização e evitando quedas futuras nas receitas de suas exportações. Porém, quando essa tendência de valorização não se confirma, ocorrendo o seu inverso, o resultado tende a ser catastrófico.

Os motivos apresentados até aqui e que justificam por que os grupos brasileiros tornaram-se multinacionais, particularmente o Votorantim, quando compreendidos isoladamente, compõem mais um caleidoscópio de suposições unilaterais do que, propriamente, uma teoria geral. Os recortes unilaterais são o resultado de uma análise ancorada no empresário e na empresa, desconsiderando-se a história, o ambiente social e econômico no qual as empresas estão inseridas. O desafio é articular, coerentemente, os movimentos dos capitais ao movimento geral do capital, sem incorrer numa inconsistência teórica.

As teorias amplamente utilizadas não dão conta de explicar, em sua totalidade, por que as empresas e

3 Ver: VM adquire ações de fábrica de aço na Argentina. Disponível em: <http://www.vmetais.com.br/pt_br/salalmprensa/releasesNoticias/Paginas/080103_AquisicaoAcerBrag.aspx>. Acesso em: 03/01/2008. 
grupos se multinacionalizam. No máximo, respondem como isso ocorre, com o enfoque apenas em elementos que compõem a aparência do processo. A essência é entender as empresas e grupos multinacionais submetidos, como qualquer outra empresa, às determinações e às contradições do modo capitalista de produção, cuja aparência é, cada vez mais, de uma concorrência oligopólica em escala mundial. São essas determinações que agem moldando o mercado e as estratégias empresariais.

Tanto as estratégias adotadas em cada país como as escalas de acumulação estão articuladas. 0 conglomerado é a representação encarnada de uma tendência de universalização do modo capitalista de produção - marcado pelo imperativo da acumulação e pelo imperativo espacial - e o principal beneficiário das diferenças espaciais, decorrente do desenvolvimento desigual nas escalas nacional, regional e mundial, tirando partido das diferentes taxas de salários, de capitais, de câmbio, de crescimento econômico etc.

\section{CONCLUSÃO}

Pelo exposto neste artigo, o Grupo Votorantim promoveu tanto a consolidação como a diversificação de seus negócios, desde meados dos anos 1930. Essa expansão econômica, setorial e espacial, porém, contou com forte papel do Estado, que patrocinou a implantação de indústrias de base por meio de isenções tarifárias sobre importação de bens de capital, subsídios financeiros, entre outras medidas. $\mathrm{O}$ apoio incondicional do Estado à industrialização sofreu uma inflexão na década de 1980, quando da crise da dívida externa e do desenvolvimentismo.

A partir dos anos 1990, quando da abertura econômica indiscriminada e do acirramento da concorrência oligopólica em escala mundial, o grupo reestruturou seus negócios, investindo em atividades em que podia competir com os maiores produtores mundiais, ingres-

\section{REFERÊNCIAS}

BARTLETT, Christopher; GHOSHAL, Sumantra. Managing Across Borders: The Transnational Solution. Boston: Harvard Business School Press, 1989.

BONELLI, Regis. As estratégias dos grandes grupos industriais brasileiros nos anos 90. Rio de Janeiro: IPEA, 1998. sou na privatização de serviços públicos e vendeu ativos considerados não estratégicos. É a partir desse momento, também, que começou a investir no exterior, mediante criação de escritórios comerciais visando divulgar marcas e aumentar as exportações. Os investimentos produtivos datam do início deste século.

Os ramos escolhidos para investimentos externos, exceto siderurgia, são aqueles em que promoveu uma forte concentração e centralização de capital, tornando-se líder no mercado interno e limitado pelo crescimento da economia. $O$ crescimento das receitas acima das taxas decrescimento do PIB do país decorre, principalmente, da extensão da acumulação da escala nacional para a regional e mundial.

Ao avaliarmos a expansão do Votorantim à luz das teorias da internacionalização, notamos que o seu avanço internacional não se deve ao controle de vantagens tecnológicas, tampouco ao conhecimento prévio e gradual de outras formas de inserção internacional, como o comércio e a exportação. Por isso, acreditamos que a sua internacionalização decorre do acirramento da concorrência oligopólica - reforçada com a abertura indiscriminada da economia - e do imperativo pela acumulação de capital. Tanto a concentração como a centralização de capital, já realizadas pelo conglomerado historicamente e em conluio com o Estado, são conduzidas, agora, não só na escala nacional, como também nas escalas regional e mundial.

Para finalizar, três pontos merecem destaque. Primeiro, apesar dos investimentos em vários países, o mercado interno continua sendo a base principal de acumulação do Votorantim. Segundo, as estratégias de acumulação envolvem todas as escalas, que se interpenetram, com o grupo acessando capitais a juros baixos em determinados mercados, onde o crescimento é menor, e investindo em outros mercados onde os juros são maiores e crescimento econômico elevado. Terceiro, as suas ações indicam que, depois dos anos 1990, quando da concentração e centralização de capital de fora para dentro, que há um movimento de centralização de capital descentrado, isto é, com participação, também, de países periféricos, dentre eles o Brasil.

CHILD, John; RODRIGUES, Suzana B. The internationalization of Chinese firms: A case for theoretical extension? Management and Organization Review, England, v. 1, n. 3, p. 381-410, 2005.

CHUDNOVSKY, Daniel; LÓPEZ, Andrés. A third wave of FDI 
from developing countries: Latin American TNCs in the 1990s, Transnational Corporations, Switzerland, v. 9, n. 2, p. 31-74, August 2000.

CORREAA, Roberto Lobato. Corporação, práticas espaciais e gestão do território. Revista Brasileira de Geografia, Rio de Janeiro, n. 5, p. 115-121, 1992.

DUNNING, John H.; HOESEL, Roger Van; NARULA, Rajneesh. Explaining the "new" wave of outward FDI from developing countries: The case of Korea and Taiwan, International Business Review, 1997b, mimeo.

DUNNING, John $\mathrm{H}$. The determinants of international production. Oxford Economic Papers, Oxford, v. 25, n. 3, p. 289-336, Nov. 1973.

FLEURY, Afonso; FLEURY, Maria Tereza Leme. Para pensar o processo de internacionalização das empresas brasileiras. INOVA, São Paulo, n. 45, p. 1-3, 2006b.

HARVEY, David. The geography of capitalist accumulation: A reconstruction of Marxian theory, Antipode, Oxford, n. 7, p. 9-21, 1975.

JOHANSON, J.; VAHLNE, J. E. The internationalization process of the firm. A model of knowledge development and increasing foreign market commitments. Journal of International Business Studies, Perth, v. 8, n.1, p. 23-32, 1977.

KIM, Linsu. Imitation to innovation: The dynamics of Korea's technological learning. Boston: Harvard Business Schools Press, 1997.

KUMAR, Krishna. Third world multinationals. A growing force in international relations. International Studies Quarterly, Bloomington, v. 26, n. 3, p. 397-424, Sept. 1982.

LALL, Sanjaya. The rise of multinationals from the third world. Third world quarterly, London, n. 3, v. 5, p. 618 - 626, 1983.

LECRAW, Donald J. Direct investment by firms from less developed countries. Oxford economic papers, Oxford, v. 29, n. 3, p. 442-457, Nov. 1977.

MARX, Karl. O capital: crítica da economia política. O processo de produção do capital. v.2. Rio de Janeiro: Bertrand, 1989.

MATHEWS, John A. Dragon multinationals: new players in the $21^{\text {st }}$ century globalization, Asia Pacific Journal Management, Singapore, n. 23, p. 5-27, 2006.
MAMIGONIAN, Armen. O processo de industrialização em São Paulo. Boletim Paulista de Geografia, São Paulo, n. 50, p. 83-102, mar. 1976.

MICHALET, Charles-Albert. O capitalismo mundial. Rio de Janeiro: Paz e Terra, 1984.

MIOTI, Luis; PERRIN, Serge; SACHWALD, Frédérique. Multinationales émergentes: un modèle Coréen?, Économie Internationale, La Revue du CEPII, Paris, n. 85, 1 trimestre 2001.

MIRANDA, José Carlos; TAVARES, Maria da Conceição. Brasil: estratégias da conglomeração. In: FIORI, José Luís (Org.). Estados e moedas no desenvolvimento das nações. Petrópolis: Vozes, 2000, p. 327-350.

NEVES, Carlos Augusto Ramos. Zinco. Sumário mineral DNPM. Brasília, 2007. Disponível em: <http://www.dnpm. gov.br/as_sets/galeriaDocumento/SumarioMineral2007/ zinco_SM2007.doc>. Acesso em: jan. 2009.

OHMAE, Kenichi. Triad power: the coming shape of global competition. New York: Free Press, 1985.

PORTER, Michael. Competitive advantage of nations. New York: Free Press, 1990.

SANTOS, Leandro Bruno. As diferentes trajetórias dos países de industrialização tardia asiáticos e latino-americanos. Caderno Prudentino de Geografia, Presidente Prudente, v. 30, p. 71-97, 2008.

SANTOS, Leandro Bruno. Reestruturação, internacionalização e novos territórios de acumulação do Grupo Votorantim. $281 \mathrm{f}$. Dissertação (Mestrado em Geografia) - Faculdade de Ciências e Tecnologia, Universidade Estadual Paulista, Presidente Prudente, 2008a.

SCANTIMBURGO, João. José Ermírio de Moraes: o homem, a obra. São Paulo: Companhia Editora Nacional, 1975.

UNCTAD. World Investment Report. Transnational corporations and the infrastructure challenge. United Nations: New York, 2008. 
